\title{
Retinal and Nonretinal Contributions to Extraclassical Surround Suppression in the Lateral Geniculate Nucleus
}

\author{
Tucker G. Fisher, Henry J. Alitto, ${ }^{\star}$ and $\odot W$. Martin Usrey* \\ Center for Neuroscience, University of California, Davis, California 95618
}

Extraclassical surround suppression is a prominent receptive field property of neurons in the lateral geniculate nucleus (LGN) of the dorsal thalamus, influencing stimulus size tuning, response gain control, and temporal features of visual responses. Despite evidence for the involvement of both retinal and nonretinal circuits in the generation of extraclassical suppression, we lack an understanding of the relative roles played by these pathways and how they interact during visual stimulation. To determine the contribution of retinal and nonretinal mechanisms to extraclassical suppression in the feline, we made simultaneous single-unit recordings from synaptically connected retinal ganglion cells and LGN neurons and measured the influence of stimulus size on the spiking activity of presynaptic and postsynaptic neurons. Results show that extraclassical suppression is significantly stronger for LGN neurons than for their retinal inputs, indicating a role for extraretinal mechanisms. Further analysis revealed that the enhanced suppression can be accounted for by mechanisms that suppress the effectiveness of retinal inputs in evoking LGN spikes. Finally, an examination of the time course for the onset of extraclassical suppression in the LGN and the size-dependent modulation of retinal spike efficacy suggests the early phase of augmented suppression involves local thalamic circuits. Together, these results demonstrate that the LGN is much more than a simple relay for retinal signals to cortex; it also filters retinal spikes dynamically on the basis of stimulus statistics to adjust the gain of visual signals delivered to cortex.

Key words: corticogeniculate; receptive field; spatial; temporal; thalamus; V1

\section{Significance Statement}

The lateral geniculate nucleus (LGN) is the gateway through which retinal information reaches the cerebral cortex. Within the LGN, neuronal responses are often suppressed by stimuli that extend beyond the classical receptive field. This form of suppression, called extraclassical suppression, serves to adjust the size tuning, response gain, and temporal response properties of neurons. Given the important influence of extraclassical suppression on visual signals delivered to cortex, we performed experiments to determine the circuit mechanisms that contribute to extraclassical suppression in the LGN. Results show that suppression is augmented beyond that provided by direct retinal inputs and delayed, consistent with polysynaptic inhibition. Importantly, these mechanisms influence the effectiveness of incoming retinal signals, thereby filtering the signals ultimately conveyed to cortex.

\section{Introduction}

Visual information is transmitted from the retina to the cerebral cortex via relay neurons in the lateral geniculate nucleus (LGN) of the dorsal thalamus. Although the retina provides only $5-10 \%$ of the synapses made with LGN neurons (Hamos et al., 1987),

\footnotetext{
Received May 14, 2016; revised 0ct. 24, 2016; accepted Nov. 17, 2016.

Author contributions: T.G.F., H.J.A., and W.M.U. designed research; T.G.F. and H.J.A. performed research; T.G.F., H.J.A., and W.M.U. analyzed data; T.G.F., H.J.A., and W.M.U. wrote the paper.

This work was supported by the National Institutes of Health (Grants EY013588 and E30 EY12576). We thank K.E. Neverkovec, C.W. Kiley, D.J. Sperka, and R. Oates-0'Brien for expert technical assistance.

*H.J.A. and W.M.U. are cosenior authors.

Correspondence should be addressed to W. Martin Usrey, Center for Neuroscience, University of California, 1544 Newton Court, Davis, CA 95618. E-mail: wmusrey@ucdavis.edu.

DOI:10.1523/JNEUROSCI.1577-16.2016

Copyright $\odot 2017$ the authors $\quad 0270-6474 / 17 / 370226-10 \$ 15.00 / 0$
}

retinal ganglion cells (RGCs) are the primary drivers of LGN activity (Sherman and Guillery, 2009). Accordingly, it has been suggested that nearly all LGN action potentials are triggered directly by retinal spikes (Kaplan and Shapley, 1984; Sincich et al., 2007). The functional dominance of the retina on the LGN is further indicated by the high degree of similarity between the classical receptive fields of synaptically connected RGCs and LGN neurons (Usrey et al., 1999; Rathbun et al., 2010). With these features of retinogeniculate communication in mind, it is important to emphasize that not all retinal spikes are transmitted to visual cortex because the LGN filters incoming spikes on the basis of prior activity, statistics of the visual environment, and behavioral state (Livingstone and Hubel, 1981; Mastronarde, 1987; Usrey et al., 1998; Lesica and Stanley, 2004; Alitto et al., 2005; Denning and Reinagel, 2005; Rathbun et al., 2007, 2010; Weyand, 
A
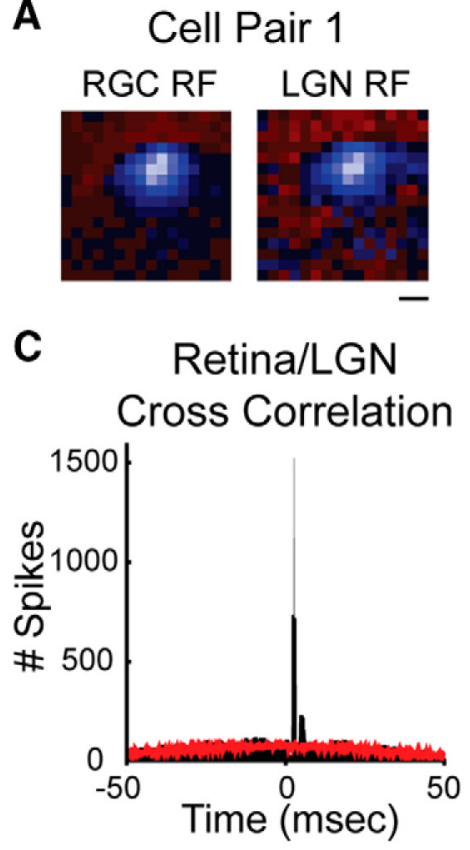

E Area Summation

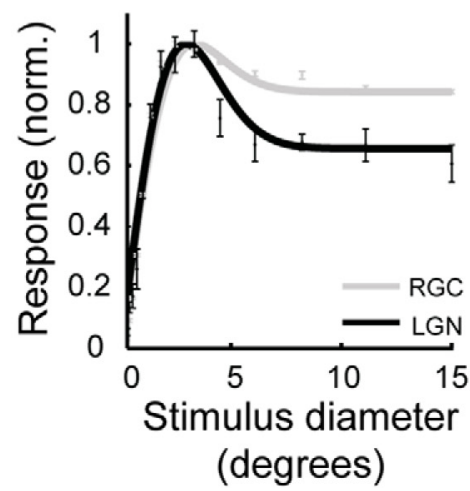

B
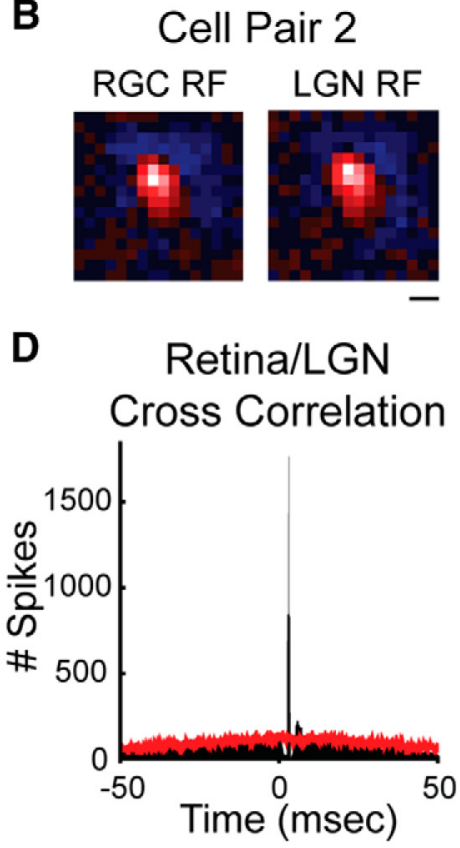

F Area Summation

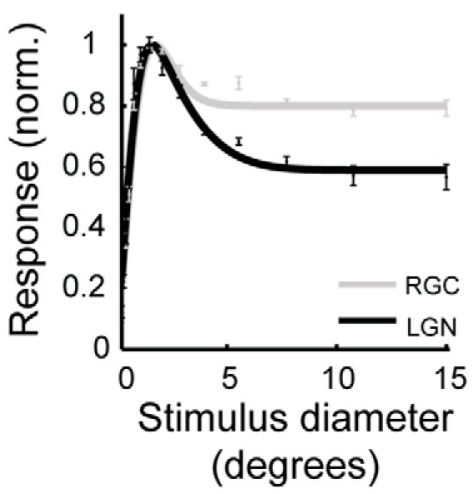

Figure 1. Receptive fields, cross-correlograms, and area summation response functions for two pairs of simultaneously recorded RGCS and LGN neurons that met the criteria for a monosynaptic connection. $\boldsymbol{A}, \boldsymbol{B}$, White noise receptive field maps on an off-center pair of cells $(\boldsymbol{A})$ and an on-center pair of cells $(\boldsymbol{B})$. In both cases, receptive fields are extremely similar in their size and spatial location. In each receptive field map, red codes for on responses and bluefor offresponses; pixel brightness indicates the strength of response. Scale bar indicates $1^{\circ}$ ofvisual angle. $\boldsymbol{C}, \boldsymbol{D}$, Cross-correlograms showing the relationship in spiking activity between the cells shown in $\boldsymbol{A}$ and $\boldsymbol{B}$ during visual stimulation with a drifting sinusoidal grating (see Materials and Methods). Retinal spikes are set to time 0 and data points show the occurrence of LGN responses relative to retinal spikes. Unshuffled and shuffled correlations are indicated in black and red, respectively. The abrupt, short latency peaks in the unshuffled cross-correlograms that rise above the shuffled correlogram indicates that the LGN neurons often fired a spike in response to a retinal spike. $E$, $F$, Area summation response functions corresponding to the same pair of cells shown in the overlying panels. Cells were excited with expanding patches of drifting gratings (see Materials and Methods). For both pair of cells, the LGN neuron (black trace) shows greater extraclassical suppression to largestimuli than the does the simultaneously recorded RGC (gray trace). Error bars indicate SEM.

2007; Chen et al., 2008; Uglesich et al., 2009; Bereshpolova et al., 2011; Moore et al., 2014; Stoelzel et al., 2015).

In addition to their classical center/surround receptive fields, RGCs and LGN neurons have a nonlinear extraclassical suppressive field that overlaps and extends beyond the classical receptive field and plays an important role in size tuning and adjusting the gain of visual responses (Jones et al., 2000; Solomon et al., 2002; Bonin et al., 2005; Alitto and Usrey, 2008; Mante et al., 2008; Alitto and Usrey, 2015a). Although extraclassical suppression is evident in the visual responses of RGCs (Solomon et al., 2006; Nolt et al., 2007; Alitto and Usrey, 2008, 2015a), the contribution of direct retinal connections to extraclassical suppression in the

LGN is unclear because both retinal and extraretinal inputs are reported to influence LGN extraclassical suppression (for review, see Usrey and Alitto, 2015).

Understanding the mechanisms that contribute to extraclassical suppression is important because augmentation of suppression within the LGN likely has significant ramifications for downstream cortical computations. For instance, because geniculocortical convergence is $\sim 6$ - to 10 fold greater than retinogeniculate convergence (Reid and Usrey, 2004), enhanced spatially expansive gain control in the geniculocortical pathway could serve as a mechanism to limit the amount of excitatory drive onto cortical target neurons. Further, whereas the classical receptive field centers of synaptically connected RGCs and LGN neurons are approximately equal in size (Usrey et al., 1999), V1 receptive fields are $\sim 3 \times$ larger (Reid and Alonso, 1995; Alonso et al., 2001). Therefore, enhanced gain-control mechanisms that extend beyond the classical receptive fields of LGN neurons could contribute to the contrastinvariant response properties of target cortical neurons (Priebe and Ferster, 2008).

To determine the contribution of retinal mechanisms to LGN extraclassical suppression, we made simultaneous recordings of monosynaptically connected RGCs and LGN neurons in the cat and compared neuronal responses with stimuli of various sizes. Our results show that extraclassical suppression is significantly stronger for LGN neurons than for their retinal inputs, indicating that suppression is augmented by extraretinal mechanisms. Moreover, the enhanced suppression evident in LGN neurons can be accounted for by mechanisms that suppress the communication of retinal spikes to the LGN. Along these lines, an analysis of the time course of size-dependent modulation of retinogeniculate communication shows that retinal spike efficacy is reduced within $\sim 7$ ms of the onset of visual responses in the LGN, suggesting that the earliest augmentation of suppression in the LGN relies on inhibition supplied by short-latency subcortical circuits. Together, these results are consistent with previous reports indicating that thalamic inhibition plays a critical role in processing sensory information (Butts et al., 2011; Crandall et al., 2015; Hirsch et al., 2015; Wimmer et al., 2015) and demonstrate that the LGN is a dynamic filter of retinal spikes capable of adjusting rapidly the gain of visual signals en route from retina to cortex.

\section{Materials and Methods}

Surgery and preparation

All surgical and experimental procedures were approved by the Animal Care and Use Committee at the University of California at Davis. As described previously, adult cats of both sexes were initially anesthetized 
with ketamine $(10 \mathrm{mg} / \mathrm{kg})$ and maintained with isoflurane $(0.7-2 \%)$. ECG, EEG, and expired $\mathrm{CO}_{2}$ were monitored for the duration of the experiment. If physiological monitoring indicated a decrease in the level of anesthesia, the amount of isoflurane delivered was increased. Animals were placed in a stereotaxic apparatus and mechanically respired. All wound margins were infused with lidocaine. A craniotomy was made above the LGN and the dura was reflected. The underlying brain was protected with a layer of agarose. The lateral margin of each eye was glued to a ring mounted to the stereotaxic frame to minimize eye movements and an intraocular guide tube was inserted through the ring to facilitate the insertion of an intraocular electrode. Once all surgical procedures were complete, animals were paralyzed with gallium triethiodide $(6-8$ $\mathrm{mg} / \mathrm{kg} / \mathrm{h}$ ). The pupils were dilated and maintained with $1 \%$ atropine sulfate and flurbiprofen sodium $(1.5 \mathrm{mg} / \mathrm{h})$ and the nictitating membranes were retracted with $10 \%$ phenylephrine. The eyes were fitted with contact lenses and focused on a monitor $1.4 \mathrm{~m}$ in front of the animal.

\section{Electrophysiological recordings and visual stimuli}

As described previously (Rathbun et al., 2010), simultaneous single-unit extracellular recordings were made from RGCs and LGN neurons with overlapping receptive fields. Retinal recordings were made with parylene-insulated tungsten electrodes (AM Systems) and LGN recordings were made with a seven-channel multielectrode array (Thomas Recording). Retinal electrodes were inserted into the posterior chamber of the eye through a guide tube attached to a custom-made manipulator. Neuronal activity was amplified, filtered (AM Systems and Thomas Recording) and sent to oscilloscopes, speakers, and a computer equipped with a 1401 data acquisition interface and the Spike 2 software package (Cambridge Electronic Design).

Visual stimuli were created with a VSG 2/5 visual stimulus generator (Cambridge Research Systems) and presented on a gamma-calibrated Sony monitor with a mean luminance of $38 \mathrm{~cd} / \mathrm{m}^{2}$. Once neurons in the retina and LGN with overlapping receptive fields were identified, receptive field maps were made using a binary white noise stimulus consisting of a $16 \times 16$ grid of squares in which each square flickered independently between black and white according to an "m-sequence" (Reid et al., 1997, See Usrey et al., 1999). The frame rate of the monitor was $140 \mathrm{~Hz}$ and stimuli were updated with each monitor frame for $2^{15}-1$ frames. To assess the influence of stimulus size on neuronal responses, drifting sinewave gratings (optimal spatial frequency, $100 \%$ contrast, $4 \mathrm{~Hz}$ ) that differed in aperture size (i.e., diameter; range: 0.1-15.0 degrees; $\geq 4$ complete sets, randomized presentation) were centered and presented over the receptive fields of recorded neurons. Grating stimuli were shown for $4 \mathrm{~s}$, followed by $4 \mathrm{~s}$ of mean gray.

\section{Data analysis}

Identifying and quantifying monosynaptic, retinogeniculate connections. Cross-correlation analysis was used to assess connectivity between simultaneously recorded neurons in the retina and LGN (Levick et al., 1972; Usrey et al., 1998). Using a bin width of $0.25 \mathrm{~ms}$, resulting crosscorrelograms show the occurrence and timing of LGN spikes relative to each retinal spike (retinal spikes set to time 0). Following previously established criteria (Mastronarde, 1987; Usrey et al., 1999; Rathbun et al., 2010), pairs of neurons were considered to be monosynaptically connected when their cross-correlogram contained an abrupt and narrow peak $(<2 \mathrm{~ms})$ that was displaced $2-6 \mathrm{~ms}$ to the right of zero and persisted after a shuffle correction. The shuffle correction, which quantifies stimulus-dependent correlations, was generated by temporally shifting LGN spike times by a multiple of the sine-wave cycle duration (e.g., 250 $\mathrm{ms}$ for $4 \mathrm{~Hz}$ temporal frequency) and calculating a shuffle correlogram from the shifted data. The statistical significance of each monosynaptic peak was determined relative to the baseline mean, which was calculated using bins from $30-50 \mathrm{~ms}$ on either side of the peak bin. Because each count in the cross-correlogram peak represents a single retinal spike relayed by the LGN neuron to the cortex, these retinal spikes were considered to be relayed spikes, whereas the remaining retinal spikes were considered to be nonrelayed. Following this logic, we calculated two values to quantify retinogeniculate communication: efficacy and contribution (Levick et al., 1972; Mastronarde, 1987; Usrey et al., 1999), where
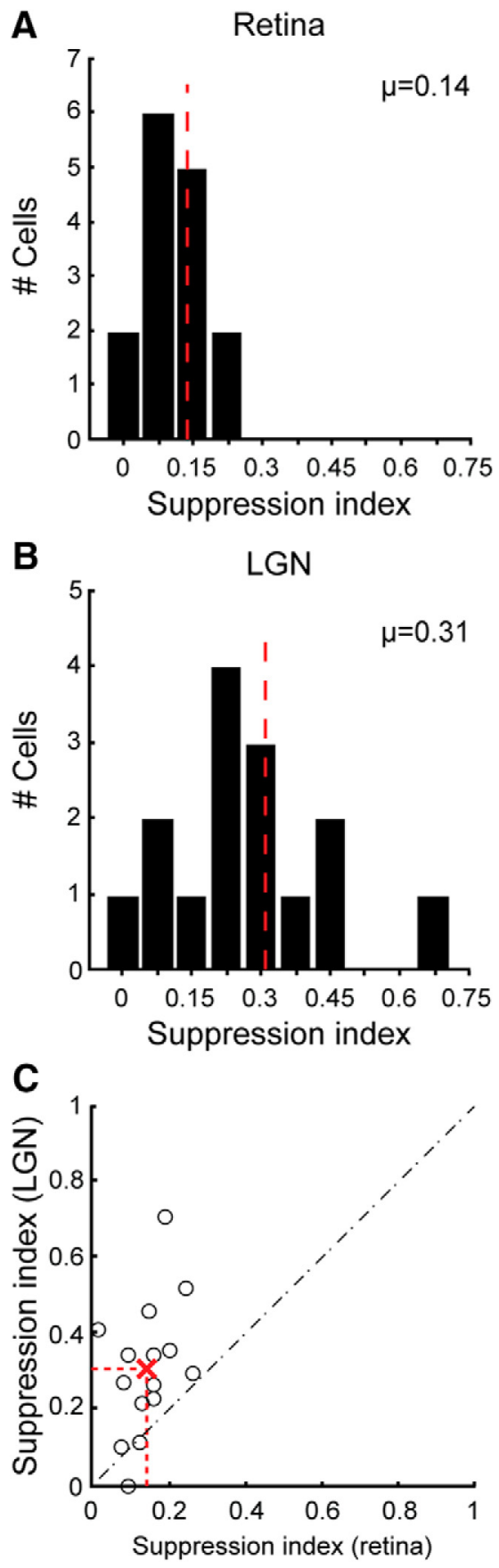

Figure 2. Extraclassical surround suppression is stronger in LGN neurons than in the RGCS that supply them. $A, B$, Histograms showing the distribution of SI values for the simultaneously RGCs and LGN neurons that met the criteria for monosynaptic connections (see Materials and Methods). Larger values indicate greater suppression. SI values were significantly greater for LGN neurons than for RGCS (SI: LGN neurons $=0.31 \pm 0.05 ; R G C s=0.14 \pm 0.02 ; p<0.002$, unpaired Student's $t$ test). Dashed red lines indicate mean values. $C$, Scatterplot showing the relationship between $S I$ values for each of the 15 simultaneously recorded cell pairs. Red " $X$ " and dashed red line indicate mean values.

efficacy is the percentage of retinal spikes that triggered LGN action potentials and contribution is the percentage of LGN action potentials that were triggered by the recorded RGC.

Area summation and extraclassical suppression. To determine the amount of extraclassical suppression exhibited by RGCs and LGN neurons, drifting sine-wave gratings $(4 \mathrm{~Hz}$, preferred spatial frequency) of various diameters (15-20 sizes, logarithmically spaced between $0.1^{\circ}$ and $15^{\circ}$ ) were presented centered over the RGC and LGN receptive fields 
A

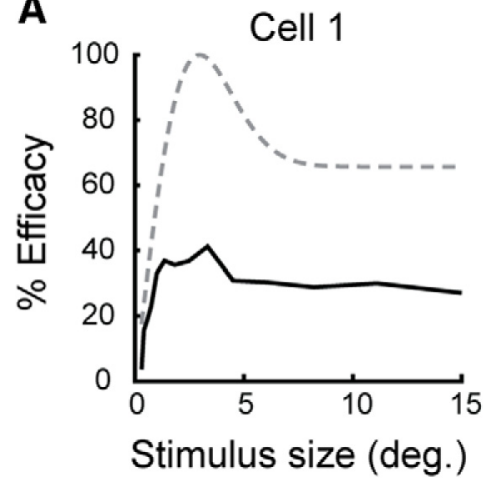

C

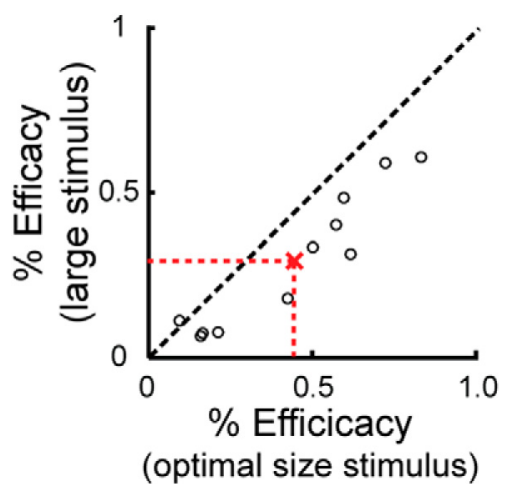

B

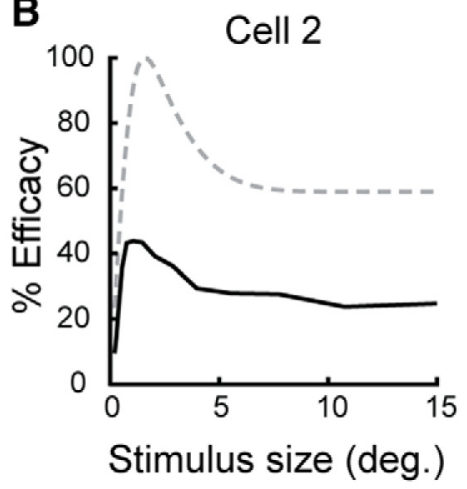

D

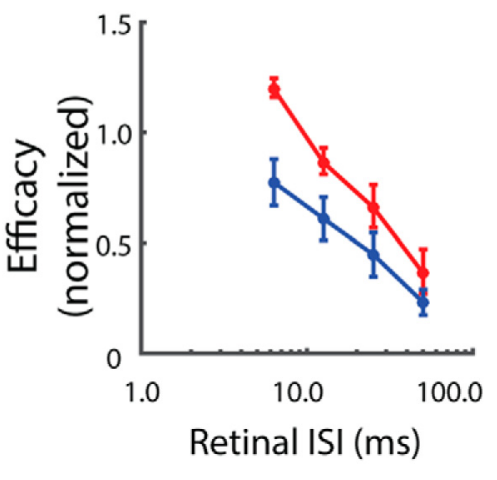

Figure 3. Influence of stimulus size on retinal spike efficacy. $A, B$, Plots showing the relationship between stimulus size and the efficacy of retinogeniculate communication (black traces), where efficacy is the percentage of retinal spikes that evoked an LGN spike, for two representative pairs of RGCs and LGN neurons. For both cell pairs, efficacy peaks rapidly and then decreases as stimuli extended into the extraclassical receptive field. For reference, the area summation response functions of the LGN neurons are represented as gray traces. C, Scatterplot showing the relationship between efficacy values calculated when cells were excited with an optimal size stimulus and a large stimulus extending into the extraclassical surround. On average, efficacy decreased with large stimuli. D, ISI efficacy functions for optimal and large stimulus responses. For each ISI, retinal spikes are less effective in evoking an LGN response when evoked by a large stimulus compared with an optimal size stimulus.

(described above). To reduce the influence of response variability, the area summation data were fit to a difference of Gaussians equation (Sceniak et al., 2001; Andolina et al., 2013; Alitto and Usrey, 2015a) as follows:

$$
\mathrm{R}(\mathrm{x})=\mathrm{K}_{\mathrm{c}} * \sum_{-\mathrm{x} / 2}^{\mathrm{x} / 2} \exp \left(-\left(2 * \mathrm{x} / \mathrm{r}_{\mathrm{c}}\right)^{2}-\mathrm{K}_{\mathrm{s}} * \sum_{-\mathrm{x} / 2}^{\mathrm{x} / 2} \exp \left(-\left(2 * \mathrm{x} / \mathrm{r}_{\mathrm{s}}\right)^{2}\right)\right.
$$

where $R(x)$ is the response evoked by diameter $x, K_{\mathrm{c}}$ is amplitude of the center subunit, $r_{\mathrm{c}}$ is the radius of the center subunit, $K_{\mathrm{s}}$ is the amplitude of the surround subunit, and $r_{\mathrm{s}}$ is the radius of the surround subunit. The surround subunit radius was taken to be the spatial extent of the extraclassical receptive field. From the fitted data, we quantified the strength of extraclassical suppression using a suppression index (SI) as follows:

$$
\text { Suppression Index }=1-\frac{\begin{array}{c}
\text { Response to large grating } \\
\text { (i.e. plateau of DOG fit) }
\end{array}}{\begin{array}{c}
\text { Response to opt. size grating } \\
\text { (i.e. peak of DOG fit) }
\end{array}}
$$

Classical versus extraclassical suppression. Depending on the experimental design and the nature of the visual stimulus, surround suppression in the retina and LGN can be triggered by either the linear mechanisms of the classical receptive field and/or the nonlinear mechanisms of the extraclassical receptive field (Bonin et al., 2005; Alitto and Usrey, 2008, 2015a). Linear suppression will occur when there is a mismatch between the visual stimulus and the polarity of the classical receptive field. For example, an on-center/off-surround neuron will display linear suppression when a white spot extends beyond the balance point of the classical center and the classical surround. In contrast, the same neu- ron will display little or no linear suppression when stimulated with a sine-wave grating of the preferred spatial frequency (Alitto and Usrey, 2015a). To determine the contribution of linear mechanisms (i.e., classical surround) to our measures of extraclassical suppression, we first created a linear model for each retinal and LGN receptive field by fitting the respective neuron's spatial frequency response function with a frequency domain difference of Gaussians equation $\left(\mathrm{DOG}_{\mathrm{f}}\right.$ ) (So and Shapley, 1981; Alitto and Usrey, 2008, 2015a):

$$
\begin{aligned}
\mathrm{SF}_{(\mathrm{x})}=\mathrm{K}_{\mathrm{c}} * \exp \left(-1 *(\mathrm{pi} * \mathrm{rc} * \mathrm{x})^{2}\right) \\
-\mathrm{Ks} * \exp \left(-1(\mathrm{pi} * \mathrm{rs} * \mathrm{x})^{2}\right)
\end{aligned}
$$

where $K_{\mathrm{c}}$ and $K_{\mathrm{s}}$ are the amplitudes of the classical center and surround, respectively, and $r_{\mathrm{c}}$ and $r_{\mathrm{s}}$ are the radii of the classical center and surround, respectively. The bestfitting DOG spatial filter was then convolved with the visual stimulus used to calculate the area summation response function predicted solely on the classical receptive field. Given that the DOG model is a good fit for RGC and LGN classical receptive fields, this analysis provides estimates for the strength of the surround suppression that would be present if the recorded neurons were simple, linear filters. Consistent with previous reports (Alitto and Usrey, 2008, 2015a), the linear model of LGN and RGC neurons predicted an average suppression index of $0.017 \pm$ 0.008 and $0.008 \pm 0.003$, respectively. By comparing this value with measured values (reported below), $\sim 5 \%$ of the measured surround suppression in the retina and LGN can be accounted for by linear mechanisms, indicating that extraclassical suppression underlies $95 \%$ of the suppression reported.

Temporal dynamics of extraclassical suppression. To determine the temporal dynamics of extraclassical suppression in the retina and LGN, we analyzed the neuronal responses evoked during the first stimulus cycle of each trial in the area summation experiments ( $4 \mathrm{~Hz}$ drifting gratings, described above). For this analysis, the spike trains from cell pairs in which the LGN cell had a suppression index $>0.2(n=11$ pairs $)$ were collapsed into population retinal and LGN spike trains. A jackknife analysis was then used to determine significance and confidence intervals for retinal and geniculate response latencies and suppression latencies. Retinal and geniculate response latencies were calculated from the activity evoked from the optimal sized stimulus, as determined from the LGN area summation response functions, and were defined as the earliest time the activity exceeded the baseline (500 ms before stimulus onset) by 3 SDs. Suppression latency was defined as the time relative to response latency that the large-grating response first became significantly less than the optimal size grating response (Welches $t$ test).

Modeling the influence of retinal interspike interval on extraclassical suppression in the LGN. Surround suppression in the retina not only decreases retinal firing rate, but also shifts the distribution of interspike intervals (ISIs) toward longer values. Because past work has shown that retinal spikes after longer ISIs are less effective in evoking a geniculate response (Mastronarde, 1987; Usrey et al., 1998; Levine and Cleland, 2001; Sincich et al., 2007; Weyand, 2007; Rathbun et al., 2010), an ISIdependent mechanism can augment suppression between the retina and LGN (Alitto and Usrey, 2015a). To estimate the contribution of retinal ISI to LGN surround suppression in the current study, we generated ISI efficacy functions for each retinogeniculate cell pair (Usrey et al., 1998). We then used these functions to model LGN spike trains by weighting each retinal spike by the average efficacy for spikes with the same ISI. 
Modeled LGN firing rates were then calculated for each stimulus diameter and predicted suppression indices were calculated as described above.

\section{Results}

We made simultaneous single-unit recordings from 15 pairs (1 X-cell pair, 14 Y-cell pairs) of monosynaptically connected RGCs and LGN neurons in the feline to determine the contribution of retinal and nonretinal mechanisms to extraclassical suppression in the LGN and the influence of stimulus size on retinogeniculate communication. Receptive fields were mapped and characterized using white noise stimuli and drifting and static sinusoidal gratings; connectivity was assessed using cross-correlation analysis on the simultaneously recorded spike trains (Usrey et al., 1998, 1999; see Materials and Methods). RGCs and LGN neurons were considered to be synaptically connected when their crosscorrelograms contained an abrupt, short-latency, statistically significant peak. This peak indicates that action potentials from the RGC had a high probability of evoking a postsynaptic spike in the LGN neuron. Receptive field maps and cross-correlograms for two representative cell pairs (one on-center pair, one off-center pair) are shown in Figure 1, $A-D$. Consistent with previous reports, monosynaptic connections were only identified between cell pairs with highly overlapping receptive fields (Usrey et al., 1998, 1999; Rathbun et al., 2010).

To determine the influence of direct retinal inputs on extraclassical surround suppression in LGN target neurons, we compared area summation response functions for each of the retinal/ LGN cell pairs in our sample. Figure $1, E$ and $F$, shows response functions for the two pairs of cells described above. The functions illustrate the responses of each neuron to an increasing aperture (0.1-15.0 $0^{\circ}$ diameter) of drifting sinusoidal grating (100\% contrast, $4 \mathrm{~Hz}$, optimal spatial frequency) on a mean gray background. In both cases, the response functions have highly overlapping rising phases, indicating that the stimulus was centered appropriately for both the RGC and the LGN neuron. More importantly, the LGN cells show significantly more suppression in their responses to large stimuli than do the RGCs $(p<0.001$, paired $t$ test). This effect was seen consistently across the sample of cell pairs. Indeed, SI values were approximately double, on average, for LGN cells compared with their simultaneously recorded RGCs (Fig. 2; SI: RGCs $=0.14 \pm 0.02$, LGN neurons $=$ $0.31 \pm 0.05 ; p<0.002$, unpaired Student's $t$ test).

Extraclassical suppression shifts the distribution of RGC ISIs toward longer values that are less effective in evoking LGN responses (Mastronarde, 1987; Usrey et al., 1998; Weyand, 2007, Rathbun et al., 2010). Because this ISI shift can serve to augment suppression between the retina and LGN (Alitto and Usrey, 2015a), we modeled area summation response functions based on the ISIs measured from each RGC and calculated SI values from these functions. Consistent with previous results (Alitto and Usrey, 2015a), we found a small but significant amount of suppression that is predicted from the size-dependent shift in the distribution of ISIs (predicted SI $=0.03 \pm 0.02 ; p<0.01$, paired $t$ test). Although significant, this increase represents just $17.6 \%$ of the difference between SI values calculated from synaptically connected RGCs and LGN neurons. Therefore, whereas extraclassical suppression in the feline LGN partially reflects suppression present in the retina that is augmented by mechanisms related to ISI and synaptic communication, additional nonretinal mechanisms appear to play a substantial role.
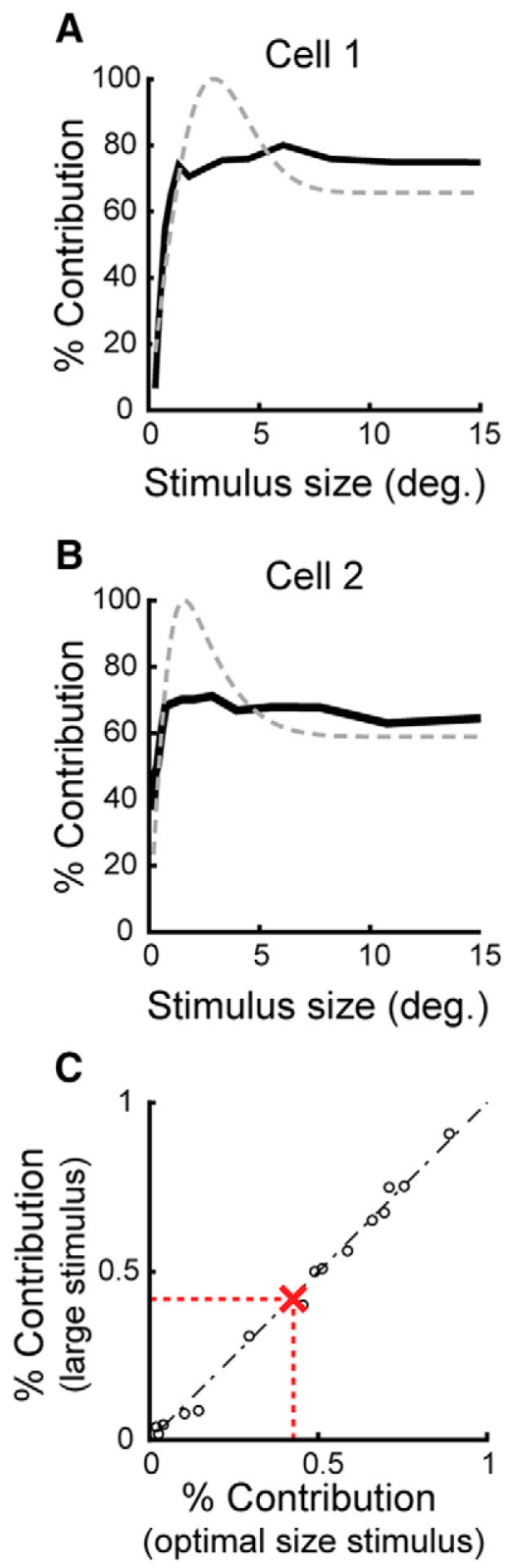

Figure 4. Influence of stimulus size on retinal spike contribution. Plots show the relationship between stimulus size and the contribution of retinal spikes in evoking an LGN response (black traces), in which contribution is the percentage of LGN spikes that were evoked by the simultaneously recorded RGC. Cell pairs in $\boldsymbol{A}$ and $\boldsymbol{B}$ are the same as those in Figure 3, $\boldsymbol{A}$ and $\boldsymbol{B}$. The gray traces show the area summation response function of the simultaneously recorded $L G N$ neuron. C, Unlike efficacy, contribution values remain constant as stimuli extend into the extraclassical receptive field, an effect seen across cell pairs.

\section{Retinogeniculate communication is modulated by stimulus size}

A potential mechanism for the enhanced size tuning of LGN neurons involves inhibition supplied by extraretinal inputs. This inhibition, activated by stimuli that extend into the extraclassical surround, would serve to move the membrane potential of LGN neurons away from the spike threshold, thereby decreasing the likelihood that a retinal spike can generate a suprathreshold response. To test this prediction, we examined the spike trains of simultaneously recorded RGCs and LGN neurons and calculated two values, efficacy and contribution, as a function of stimulus size. In this analysis, efficacy is the percentage of retinal spikes 
A

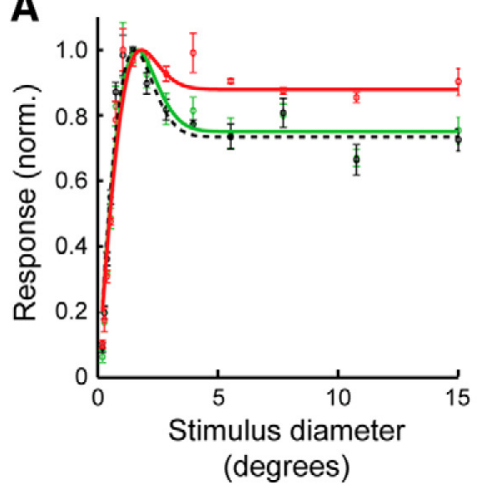

B

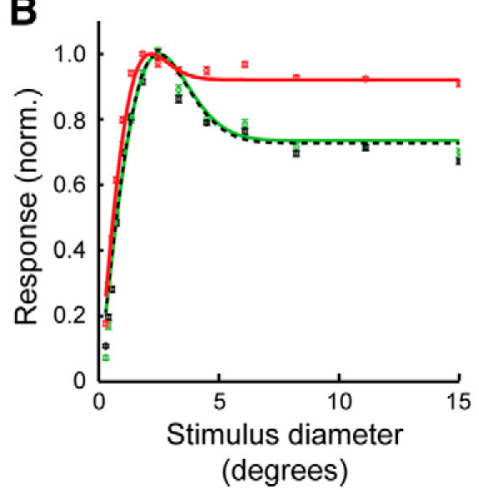

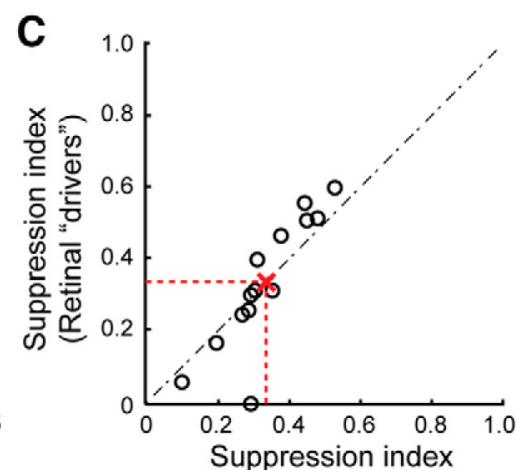

(LGN cells)

Figure 5. Extraclassical suppression in the LGN can be accounted for by a selective filtering of retinal spikes. $\boldsymbol{A}, \boldsymbol{B}$, Normalized area summation response functions corresponding to different categories of spikes produced by two representative pairs of synaptically connected RGCs and LGN neurons. The red, green, and dashed black traces show response functions calculated from all of the RGC's spikes, only the retinal spikes that were successful (i.e., drivers) in evoking LGN responses, and all LGN spikes, respectively. For both pairs of cells, successful retinal spikes show the same degree of extraclassical suppression as the postsynaptic LGN neuron. C, Scatterplot showing the similarity between SI values for successful retinal spikes versus all LGN spikes for each cell pair in the sample. The red " $X$ " and dashed lines indicate mean values.

that evoke a spike in the LGN neuron and contribution is the percentage of LGN spikes that were evoked from the RGC. As shown in Figure 3, $A$ and $B$, for two representative pairs of neurons, communication between the retina and LGN was indeed influenced by stimulus size. In particular, efficacy increased rapidly with stimulus size, reached a peak and then decreased for larger stimuli. Moreover, the overall shape of the efficacy response functions (black lines) resembled that of the LGN cells' area summation response functions (dashed gray lines).

Across our sample of cell pairs, efficacy for large stimuli was reduced to $66 \pm 7 \%$ of optimal size efficacy (Fig. $3 C$; $p<0.05$, paired $t$ test), supporting the view that inhibition filters retinal spikes trains differentially and in a stimulus-dependent manner. The suppressive influence of stimulus size on retinogeniculate communications was also evident in ISI efficacy functions calculated from optimal and large stimulus responses. As shown in Figure $3 D$, increasing stimulus diameter into the extraclassical surround caused a marked downward shift in the ISI efficacy curve, indicating that retinal spikes at a given ISI are less effective in driving LGN responses. Unlike measures of efficacy, contribution response functions were essentially flat after the initial rise (Fig. 4A,B), indicating that the percentage of LGN spikes evoked by the recorded RGC does not change as a function of size (Fig. $4 C ; p=0.36$, paired $t$ test).

To determine the extent to which size tuning in the LGN can be accounted for by the combination of two mechanisms, weak tuning initially generated within the retina and the filtering of retinal spikes by LGN neurons, we calculated area summation response functions for each RGC in our sample using only the subset of retinal spikes that directly evoked LGN responses (i.e., retinal spikes contributing to the peak of each pair's crosscorrelogram) and compared these functions with those calculated using all of the spikes produced by the RGC and with all of the spikes produced by the simultaneously recorded LGN neuron. Figure 5, $A$ and $B$, shows the results of this analysis for two representative pairs of cells. In both cases, mechanisms within the retina resulted in modest extraclassical suppression (red traces), whereas mechanisms beyond the retina reduced the percentage of relayed retinal spikes at large stimulus sizes (green traces). Importantly, the area summation response functions calculated from the successful (i.e., relayed) retinal spikes were similar to those calculated from the spikes of the simultaneously recorded LGN cell (black dashed traces). Accordingly, there was not a sig- nificant difference between the suppression index values of the LGN cells in our sample and the index values for the successful retinal spikes supplied by the simultaneously recorded RGCs (Fig. $5 C, p=0.77$, paired $t$ test). This result is striking given the high likelihood that the LGN cells in the sample also received input from other (nonrecorded) RGCs. This result is also consistent with the view that the postsynaptic mechanism(s) governing the filtering of retinal spikes has a similar influence on incoming spikes regardless of the RGC that produced them.

\section{Temporal dynamics of extraclassical suppression in the LGN}

Polysynaptic circuits involving recurrent connections between the LGN and the thalamic reticular nucleus and/or feedback from the cortex have been proposed to influence extraclassical suppression in the LGN (for review, see Sillito and Jones, 2002; Usrey and Alitto, 2015). If these circuits indeed have a role, then one would expect a delay in suppression relative to the onset of the excitatory response, as assessed by changes in firing rate and retinal spike efficacy (as shown in Fig. 3). To test this prediction, as well as to place constraints on the potential circuits involved, we measured the relative time course of the excitatory and suppressive influences evoked by the first cycle of the drifting sine-wave grating stimulus used in the experiments described above. This analysis was performed on all RGC-LGN cell pairs in which the suppression index for the LGN cell was $>0.2$ ( $n=11$ pairs). Response latency was defined as the earliest time after stimulus onset (optimal size grating) that activity exceeded baseline levels (assessed during the $500 \mathrm{~ms}$ period before stimulus presentation) by 3 SDs and suppression latency was defined as the time relative to response latency that the large-grating response first became significantly less than the optimal size grating response $(p<$ $0.01, t$ test).

As expected, there was a significant difference between the response latencies of RGCs and LGN neurons in our sample of monosynaptically connected cell pairs (mean response latency: RGCs = $14.7 \pm 0.3 \mathrm{~ms} ; \mathrm{LGN}$ neurons $=19.1 \pm 0.7 \mathrm{~ms}, p<10^{-6}, t$ test $)$. More importantly, the temporal profiles of the responses to optimal size and large-diameter gratings began to diverge for both the RGCs and LGN neurons shortly after response onset (Fig. 6A,B). On average, RGC suppression latency was delayed by $5.0 \pm 0.2 \mathrm{~ms}$ relative to the response onset of RGCs and LGN suppression latency was delayed $8.0 \pm 0.5 \mathrm{~ms}$ relative to the response onset of LGN neurons (Fig. 6C). It is worth noting that LGN suppression was preceded by a brief period of response facilitation (large stimulus response $>$ op- 
A
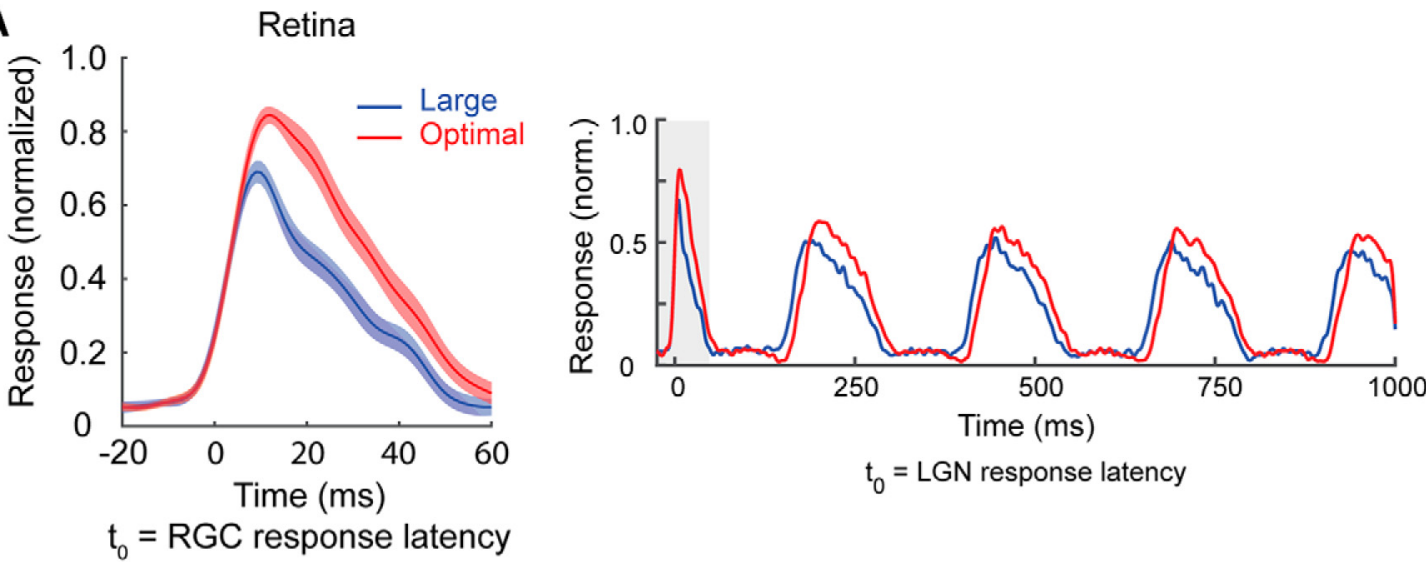

B
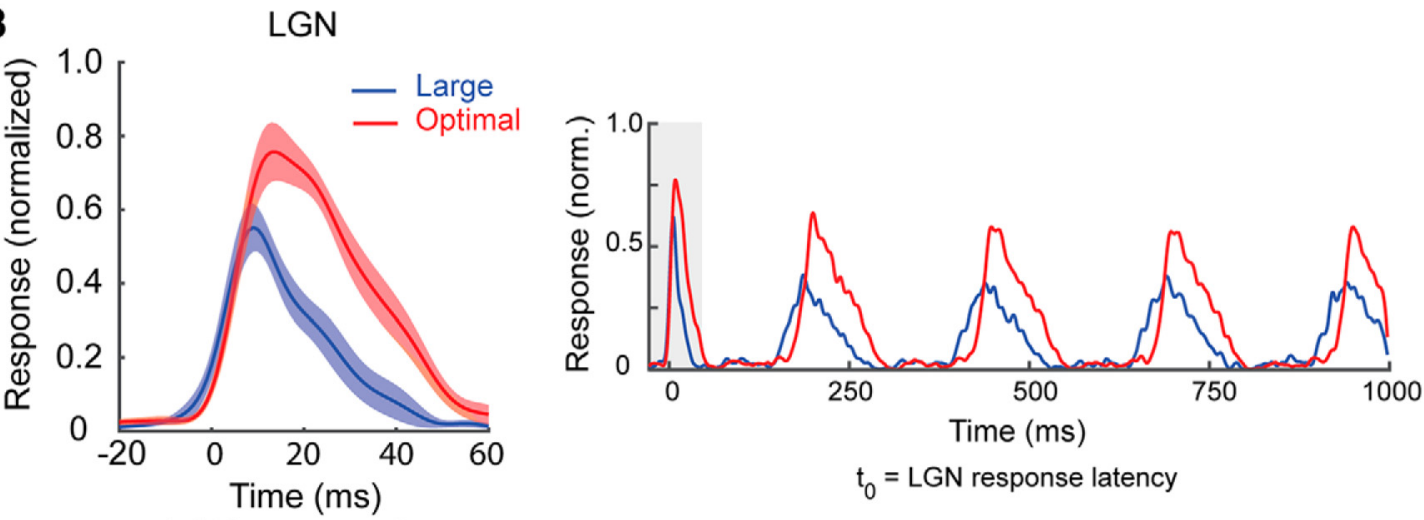

$\mathrm{t}_{0}=\mathrm{LGN}$ response latency
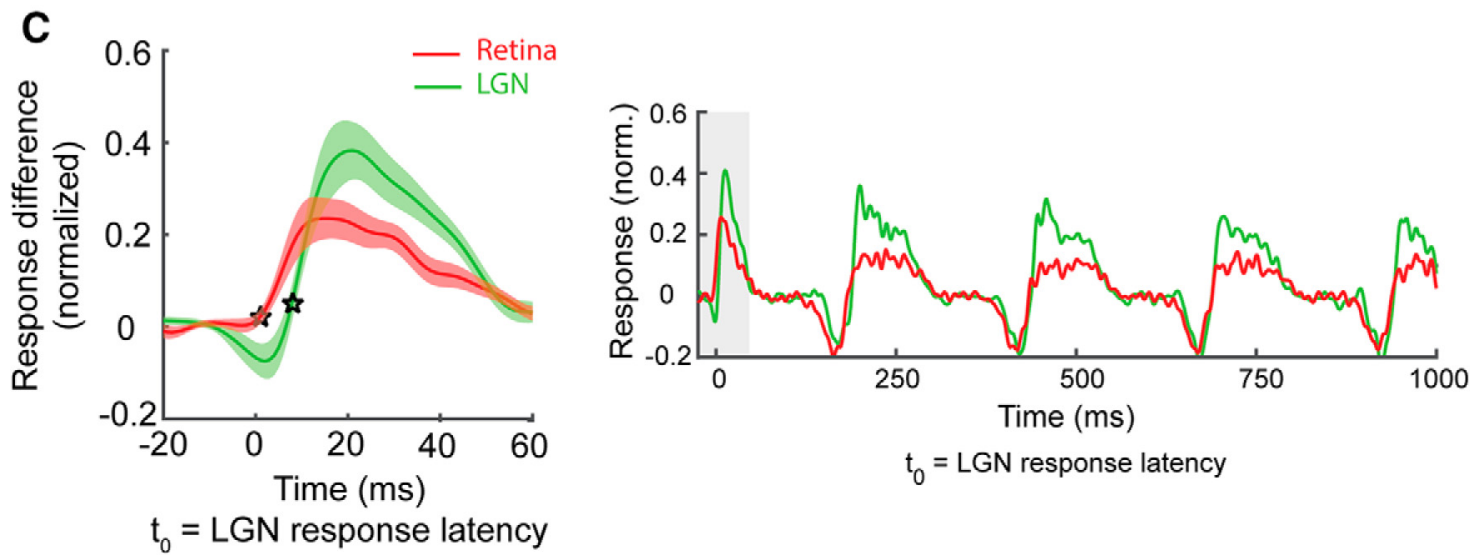

Figure 6. Extraclassical suppression emerges early in retinal and geniculate responses. $A$, Population $\mathrm{RGC}$ temporal response profile calculated from the first cycle of a $4 \mathrm{~Hz}$ drifting sine-wave grating (starting phase set to each cell's preferred phase). Red curve shows the time course of responses to an optimal size grating stimulus; blue curve shows the time course of responses to a large grating stimulus. The timing of responses is shown relative to $t_{(0)}$, which is the response latency of the RGCs when stimulated with an optimal size stimulus. RGC response latency was calculated separately for each cell. Shaded area corresponds to $95 \%$ confidence intervals. $B$, Population LGN temporal response profile (details the same as in $A$ ). $t_{(0)}$ is the $L G N$ response latency of the $L G N$ cells to an optimal size stimulus. C, Difference curves (optimal - large) for the RGCs (red) and LGN neurons (green). Stars indicate the suppression latencies for the RGCs and LGN neurons. $t_{(0)}$ is the LGN response latency for optimal size stimuli.

timal stimulus response). This facilitation appears to be caused by a size-dependent phase advance that was present in the both the retina and LGN, but was not measureable in the retina until the second stimulus cycle (Fig. 6, right column). Although the mechanisms underlying this phase advance are unknown, it is tempting to speculate that they share features in common with those associated with contrast gain control and contrast-dependent phase advance (Shapley and Victor, 1978; Rathbun et al., 2016).

In a final analysis, we examined the influence of stimulus size on the temporal profile of retinal spike efficacy to determine when augmented suppression is first evident as a reduction in the communication of spikes between the retina and LGN. Given that the magnitude of suppression in the LGN can be largely accounted for by size-dependent changes in retinal spike efficacy (Fig. 5C), we reasoned that retinal spike efficacy for large stimuli should become less than that for optimal stimuli at a delay similar to that identified from firing rate changes. As shown in Figure 7, $A$ and $B$, the efficacy of retinogeniculate communication was indeed dynamic with respect to the onset of visual responses. The earliest time retinal spike efficacy for large stimuli decreased sig- 


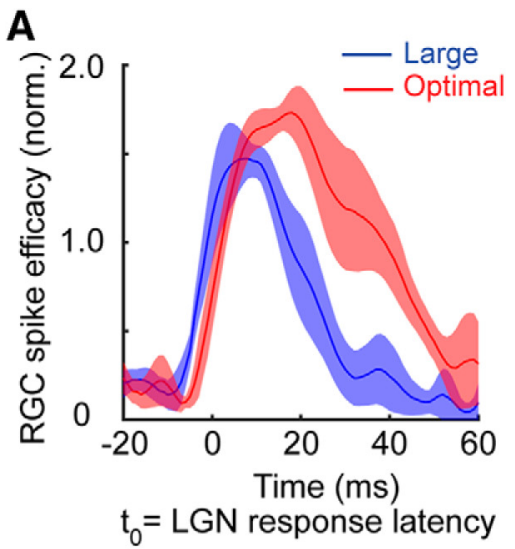

B

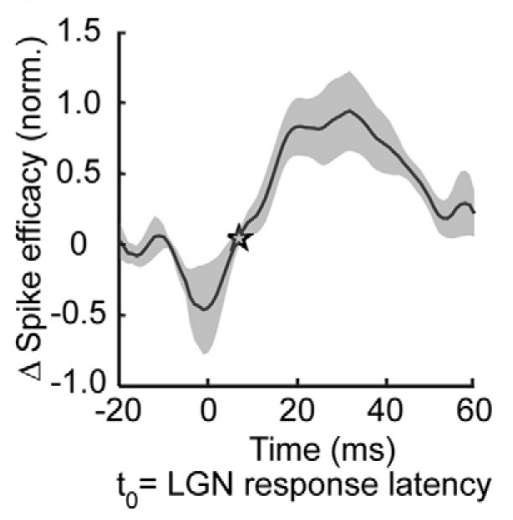

Figure 7. Temporal dynamics of retinal spike efficacy illustrate the augmentation of extraclassical suppression in the LGN. $\boldsymbol{A}$, Retinal spike efficacy as a function of time. Data points correspond to the time of individual retinal spikes relative to $t_{(0)}$, which represents $L G N$ response latency to an optimal size stimulus. Efficacy values were normalized to the mean value separately for each $\mathrm{RGC}$ and then averaged to yield population curves. Red curve corresponds to the efficacy values of cell pairs stimulated with an optimal size stimulus; blue curve corresponds to the efficacy values of cell pairs stimulated with a large stimulus. $\boldsymbol{B}$, Size-dependent efficacy differences as a function of time (optimal size efficacy - large size efficacy). Star indicates the earliest time after response onset that retinal spike efficacy is significantly less for large size stimuli compared with optimal size stimuli.

nificantly ( $p<0.01, t$ test) below that for optimal size stimuli was $7.0 \pm 0.8 \mathrm{~ms}$ with respect to the onset of visual responses in the LGN. Results also identified a brief period of facilitation in retinal spike efficacy with large stimuli that preceded suppression. In summary, these findings indicate the involvement of extraretinal mechanisms in modulating communication between the retina and LGN and reveal that the early phase of augmented suppression in the LGN occurs with a short delay after the onset of visual responses.

\section{Discussion}

The goal of this study was to determine the contribution of retinal and nonretinal mechanisms to extraclassical suppression in the feline LGN and the influence of stimulus size on retinogeniculate communication. Although this nonlinear receptive field property is present in both the retina and LGN (Levick et al., 1972; Murphy and Sillito, 1987; Felisberti and Derrington, 1999; Przybyszewski et al., 2000; Ruksenas et al., 2000; Girardin et al., 2002; Sillito and Jones, 2002; Solomon et al., 2002, 2006; Webb et al., 2002, 2005; Nolt et al., 2004, 2007; Alitto and Usrey, 2008, 2015a), little was known about the extent to which extraclassical suppression in the feline LGN is inherited from the retina. By simultaneously re- cording the spiking activity of monosynaptically connected RGCs and LGN neurons, this study demonstrates that extraclassical suppression is significantly stronger for LGN neurons than for their retinal inputs. Results further show that the percentage of retinal spikes that evoke LGN responses decreases as stimulus size increases, suggesting that extraretinal mechanisms such as thalamic inhibition filter retinal input in a stimulus-dependent manner. In support of this view, an examination of area summation response functions generated only from the subset of retinal spikes that evoke LGN responses reveals that extraclassical suppression in the LGN can be fully accounted for by filtering the incoming retinal spike train at the level of the LGN. Moreover, the augmentation of LGN surround suppression occurs shortly after the excitatory response onset in the LGN, leaving little time for other, nonlocal circuits to be involved. Interestingly, this degree of extraretinal influence on extraclassical suppression may be a hallmark of the feline LGN because extraclassical suppression in the monkey LGN relies more heavily on retinal mechanisms (Alitto and Usrey, 2008).

Because RGC synapses onto LGN neurons are strictly excitatory, the augmented extraclassical surrounds of LGN neurons likely rely on polysynaptic circuits involving inhibitory neurons. Along these lines, an analysis of the time course of size-dependent modulation of retinal spike efficacy suggests that the early phase of extraclassical suppression involves GABAergic local circuits within the LGN or between the thalamic reticular nucleus (TRN) and the LGN because the onset of suppression is typically too fast ( $\sim 7$ ms delay) for polysynaptic circuits involving the cortex. Moreover, because local interneurons and TRN neurons often prefer stimuli comparable in size to stimuli that are optimal for LGN relay cells (Wang et al., 2011; Vaingankar et al., 2012), the augmented and nonlinear suppressive fields of LGN relay neurons presumably result from convergent input from small ensembles of inhibitory neurons with overlapping and nearby receptive fields.

Several lines of evidence indicate that corticogeniculate feedback neurons also play a role in extraclassical suppression in the feline LGN (Murphy and Sillito, 1987; Sillito and Jones, 2002; Webb et al., 2002; Nolt et al., 2007; Olsen et al., 2012). However, given the relatively long visual response latencies of V1 neurons compared with LGN neurons along with the time required for action potentials to propagate from the cortex to the LGN and the added time needed to engage polysynaptic circuits for inhibition within the thalamus (Harvey, 1978; Tsumoto and Suda, 1980; Hirsch et al., 1998; Usrey et al., 1999; Alonso et al., 2001; Briggs and Usrey, 2005, 2009; Liang et al., 2008), it seems unlikely that corticogeniculate feedback has much of an influence on the early phase of extraclassical suppression in the LGN. With this in mind, feedback could certainly contribute to later phases of suppression. If so, then the influence of feedback is likely to be complex because feedback axons provide direct excitatory input onto LGN relay neurons and input onto local interneurons and GABAergic neurons in the reticular nucleus that in turn project onto relay neurons (Jones, 2006; Ulrich et al., 2007; Sherman and Guillery, 2009; Cox, 2014). Moreover, synaptic communication at all of these synapses, including retinogeniculate synapses, is dynamic and dependent on the firing rate of presynaptic neurons (Crandall et al., 2015; Alitto and Usrey, 2015a,2015b). Regardless of when the inhibition arrives, results from the current study suggest that the inhibition serves to reduce the efficacy of retinal spikes in evoking LGN responses because extraclassical suppression in the LGN can be accounted for by a selective filtering of the incoming retinal spike train. With that in mind, it is important to 
note that inhibition is not the only mechanism that serves to filter retinal spikes because RGCs in the cat experience a modest amount of extraclassical suppression that not only reduces the firing rate of RGCs, but also shifts the distribution of ISIs in the retinal spike train toward longer ISIs, thereby decreasing temporal summation in LGN cells and the likelihood of a postsynaptic response (Usrey et al., 1998, Alitto and Usrey, 2015a).

Finally, given that the two sources of inhibition onto LGN relays, local interneurons and TRN neurons, are likely to have roles in both extraclassical suppression and state-dependent changes in thalamocortical activity, it is interesting to consider whether behavioral state has an influence on extraclassical suppression. In support of this possibility, an examination of contrast response functions generated from LGN neurons in alert and anesthetized animals indicates that anesthesia acts to scale neuronal firing rate in a divisive fashion over a wide range of contrasts (Alitto et al., 2011). Likewise, spatial attention has been shown to augment LGN responses, presumably by decreasing inhibition from the TRN (McAlonan et al., 2006, 2008). Because thalamic inhibition is modulated by the brainstem, basal forebrain, and numerous cortical areas, extraclassical suppression may be a dynamic property of LGN neurons that can be modulated differentially by behavior and behavioral state to gate the thalamocortical transmission of retinal information to cortex.

\section{References}

Alitto HJ, Usrey WM (2008) Origin and dynamics of extraclassical suppression in the lateral geniculate nucleus of the macaque monkey. Neuron 57:135-146. CrossRef Medline

Alitto HJ, Usrey WM (2015a) Surround suppression and temporal processing of visual signals. J Neurophysiol 113:2605-2617. CrossRef Medline

Alitto HJ, Usrey WM (2015b) Dissecting the dynamics of corticothalamic feedback. Neuron 86:605-607. CrossRef Medline

Alitto HJ, Weyand TG, Usrey WM (2005) Distinct properties of stimulusevoked bursts in the lateral geniculate nucleus. J Neurosci 25:514-523. CrossRef Medline

Alitto HJ, Moore BD 4th, Rathbun DL, Usrey WM (2011) A comparison of visual responses in the lateral geniculate nucleus of alert and anaesthetized macaque monkeys. J Physiol 589:87-99. CrossRef Medline

Alonso JM, Usrey WM, Reid RC (2001) Rules of connection for neurons in the lateral geniculate nucleus and visual cortex. J Neurosci 21:4002-4015. Medline

Andolina IM, Jones HE, Sillito AM (2013) Effects of cortical feedback on the spatial properties of relay cells in the lateral geniculate nucleus. J Neurophysiol 109:889-899. CrossRef Medline

Bereshpolova Y, Stoelzel CR, Zhuang J, Amitai Y, Alonso JM, Swadlow HA (2011) Getting drowsy? Alert/nonalert transitions and visual thalamocortical network dynamics. J Neurosci 31:17480-17487. CrossRef Medline

Bonin V, Mante V, Carandini M (2005) The suppressive field of neurons in lateral geniculate nucleus. J Neurosci 25:10844-10856. CrossRef Medline

Briggs F, Usrey WM (2005) Temporal properties of feedforward and feedback pathways between the thalamus and visual cortex in the ferret. Thalamus and Related Systems 3:133-139. CrossRef Medline

Briggs F, Usrey WM (2009) Parallel processing in the corticogeniculate pathway of the macaque monkey. Neuron 62:135-146. CrossRef Medline

Butts DA, Weng C, Jin J, Alonso JM, Paninski L (2011) Temporal precision in the visual pathway through the interplay of excitation and stimulusdriven suppression. J Neurosci 31:11313-11327. CrossRef Medline

Chen Y, Martinez-Conde S, Macknik SL, Bereshpolova Y, Swadlow HA, Alonso JM (2008) Task difficulty modulates the activity of specific neuronal populations in primary visual cortex. Nat Neurosci 11:974-982. CrossRef Medline

Cox CL (2014) Complex regulation of dendritic transmitter release from thalamic interneurons. Curr Opin Neurobiol 29:126-132. Medline

Crandall SR, Cruikshank SJ, Connors BW (2015) A corticothalamic switch: controlling the thalamus with dynamic synapses. Neuron 86:768-782. CrossRef Medline

Denning KS, Reinagel P (2005) Visual control of burst priming in the anes- thetized lateral geniculate nucleus. J Neurosci 25:3531-3538. CrossRef Medline

Felisberti F, Derrington AM (1999) Long-range interactions modulate the contrast gain in the lateral geniculate nucleus of cats. Vis Neurosci 16: 943-956. Medline

Girardin CC, Kiper DC, Martin KA (2002) The effect of moving textures on the responses of cells in the cat's dorsal lateral geniculate nucleus. Eur J Neurosci 16:2149-2156. CrossRef Medline

Hamos JE, Van Horn SC, Raczkowski D, Sherman SM (1987) Synaptic circuits involving an individual retinogeniculate axon in the cat. J Comp Neurol 259:165-192. CrossRef Medline

Harvey AR (1978) Characteristics of corticothalamic neurons in area 17 of the cat. Neurosci Lett 7:177-181. CrossRef Medline

Hirsch JA, Alonso JM, Reid RC, Martinez LM (1998) Synaptic integration in striate cortical simple cells. J Neurosci 18:9517-9528. Medline

Hirsch JA, Wang X, Sommer FT, Martinez LM (2015) How inhibitory circuits in the thalamus serve vision. Annu Rev Neurosci 38:309-329. CrossRef Medline

Jones EG 2006 The thalamus, Ed 2. Cambridge: Cambridge University.

Jones HE, Andolina IM, Oakely NM, Murphy PC, Sillito AM (2000) Spatial summation in lateral geniculate nucleus and visual cortex. Exp Brain Res 135:279-284. CrossRef Medline

Kaplan E, Shapley R (1984) The origin of the S (slow) potential in the mammalian lateral geniculate nucleus. Exp Brain Res 55:111-116. Medline

Lesica NA, Stanley GB (2004) Encoding of natural scene movies by tonic and burst spikes in the lateral geniculate nucleus. J Neurosci 24:1073110740. CrossRef Medline

Levick WR, Cleland BG, Dubin MW (1972) Lateral geniculate neurons of cat: retinal inputs and physiology. Invest Ophthalmol 11:302-311. Medline

Levine MW, Cleland BG (2001) An analysis of the effect of retinal ganglion cell impulses upon the firing probability of neurons in the dorsal lateral geniculate nucleus of the cat. Brain Res 902:244-254. CrossRef Medline

Liang Z, Shen W, Sun C, Shou T (2008) Comparative study on the offset responses of simple cells and complex cells in the primary visual cortex of the cat. Neuroscience 156:365-373. CrossRef Medline

Livingstone MS, Hubel DH (1981) Effects of sleep and arousal on the processing of visual information in the cat. Nature 291:554-561. CrossRef Medline

Mante V, Bonin V, Carandini M (2008) Functional mechanisms shaping lateral geniculate responses to artificial and natural stimuli. Neuron 58: 625-638. CrossRef Medline

Mastronarde DN (1987) Two classes of single-input X-cells in cat lateral geniculate nucleus. II. Retinal inputs and the generation of receptive-field properties. J Neurophysiol 57:381-413. Medline

McAlonan K, Cavanaugh J, Wurtz RH (2006) Attentional modulation of thalamic reticular neurons. J Neurosci 26:4444-4450. CrossRef Medline

McAlonan K, Cavanaugh J, Wurtz RH (2008) Guarding the gateway to cortex with attention in visual thalamus. Nature 456:391-394. CrossRef Medline

Moore BD 4th, Rathbun DL, Usrey WM, Freeman RD (2014) Spatiotemporal flow of information in the early visual pathway. Eur J Neurosci 39:593601. CrossRef Medline

Murphy PC, Sillito AM (1987) Corticofugal feedback influences the generation of length tuning in the visual pathway. Nature 329:727-729. CrossRef Medline

Nolt MJ, Kumbhani RD, Palmer LA (2004) Contrast-dependent spatial summation in the lateral geniculate nucleus and retina of the cat. J Neurophysiol 92:1708-17017. CrossRef Medline

Nolt MJ, Kumbhani RD, Palmer LA (2007) Suppression at high spatial frequencies in the lateral geniculate nucleus of the cat. J Neurophysiol 98: 1167-1180. CrossRef Medline

Olsen SR, Bortone DS, Adesnik H, Scanziani M (2012) Gain control by layer six in cortical circuits of vision. Nature 483:47-52. CrossRef Medline

Priebe NJ, Ferster D (2008) Inhibition, spike threshold, and stimulus selectivity in primary visual cortex. Neuron 57:482-497. CrossRef Medline

Przybyszewski AW, Gaska JP, Foote W, Pollen DA (2000) Striate cortex increases contrast gain of macaque LGN neurons. Vis Neurosci 17:485494. CrossRef Medline

Rathbun DL, Alitto HJ, Weyand TG, Usrey WM (2007) Interspike interval analysis of retinal ganglion cell receptive fields. J Neurophysiol 98:911919. CrossRef Medline 
Rathbun DL, Warland DK, Usrey WM (2010) Spike timing and information transmission at retinogeniculate synapses. J Neurosci 30:1355813566. CrossRef Medline

Rathbun DL, Alitto HJ, Warland DK, Usrey WM (2016) Stimulus contrast and retinogeniculate signal processing. Front Neural Circuits 10:8. CrossRef Medline

Reid RC, Alonso JM (1995) Specificity of monosynaptic connections from thalamus to visual cortex. Nature 378:281-284. CrossRef Medline

Reid RC, Usrey WM (2004) Functional connectivity in the pathway from retina to striate cortex. In: The visual neurosciences (Chalupa LM, Werner JS, eds), pp 673-679. Cambridge, MA: MIT.

Reid RC, Victor JD, Shapley RM (1997) The use of m-sequences in the analysis of visual neurons: linear receptive field properties. Vis Neurosci 14:1015-1027. Medline

Ruksenas O, Fjeld IT, Heggelund P (2000) Spatial summation and centersurround antagonism in the receptive field of single units in the dorsal lateral geniculate nucleus of cat: comparison with retinal input. Vis Neurosci 17:855-870. CrossRef Medline

Sceniak MP, Hawken MJ, Shapley R (2001) Visual spatial characterization of macaque V1 neurons. J Neurophysiol 85:1873-1887. Medline

Shapley RM, Victor JD (1978) The effect of contrast on the transfer properties of cat retinal ganglion cells. J Physiol 285:275-298. CrossRef Medline

Sherman SM, Guillery RW (2009) Exploring the thalamus and its role in cortical function, Ed 2. Cambridge, MA: MIT.

Sillito AM, Jones HE (2002) Corticothalamic interactions in the transfer of visual information. Philos Trans R Soc Lond B Biol Sci 357:1739-1752. CrossRef Medline

Sincich LC, Adams DL, Economides JR, Horton JC (2007) Transmission of spike trains at the retinogeniculate synapse. J Neurosci 27:2683-2692. CrossRef Medline

So YT, Shapley R (1981) Spatial tuning of cells in and around lateral geniculate nucleus of the cat: $\mathrm{X}$ and $\mathrm{Y}$ relay cells and the perigeniculate interneurons. J Neurophysiol 45:107-120. Medline

Solomon SG, White AJ, Martin PR (2002) Extraclassical receptive field properties of parvocellular, magnocellular, and koniocellular cells in the primate lateral geniculate nucleus. J Neurosci 22:338-349. Medline

Solomon SG, Lee BB, Sun H (2006) Suppressive surrounds and contrast gain in magnocellular-pathway retinal ganglion cells of macaque. J Neurosci 26:8715-8726. CrossRef Medline
Stoelzel CR, Huff JM, Bereshpolova Y, Zhuang J, Hei X, Alonso JM, Swadlow HA (2015) Hour-long adaptation in the awake early visual system. J Neurophysiol 114:1172-1182. CrossRef Medline

Tsumoto T, Suda K (1980) Three groups of cortico-geniculate neurons and their distribution in binocular and monocular segments of cat striate cortex. J Comp Neurol 193:223-236. CrossRef Medline

Uglesich R, Casti A, Hayot F, Kaplan E (2009) Stimulus size dependence of information transfer from retina to thalamus. Front Syst Neurosci 3:10. CrossRef Medline

Ulrich D, Besseyrias V, Bettler B (2007) Functional mapping of GABA(B)receptor subtypes in the thalamus. J Neurophysiol 98:3791-3795. CrossRef Medline

Usrey WM, Alitto HJ (2015) Visual functions of the thalamus. Annu Rev Vis Sci 1:351-371. CrossRef

Usrey WM, Reppas JB, Reid RC (1998) Paired-spike interactions and synaptic efficacy of retinal inputs to the thalamus. Nature 395:384-387. CrossRef Medline

Usrey WM, Reppas JB, Reid RC (1999) Specificity and strength of retinogeniculate connections. J Neurophysiol 82:3527-3540. Medline

Vaingankar V, Soto-Sanchez C, Wang X, Sommer FT, Hirsch JA (2012) Neurons in the thalamic reticular nucleus are selective for diverse and complex visual features. Front Integr Neurosci 6:118. CrossRef Medline

Wang X, Vaingankar V, Soto Sanchez C, Sommer FT, Hirsch JA (2011) Thalamic interneurons and relay cells use complementary synaptic mechanisms for visual processing. Nat Neurosci 14:224-231. CrossRef Medline

Webb BS, Tinsley CJ, Barraclough NE, Easton A, Parker A, Derrington AM (2002) Feedback from V1 and inhibition from beyond the classical receptive field modulates the responses of neurons in the primate lateral geniculate nucleus. Vis Neurosci 19:583-592. CrossRef Medline

Webb BS, Tinsley CJ, Vincent CJ, Derrington AM (2005) Spatial distribution of suppressive signals outside the classical receptive field in lateral geniculate nucleus. J Neurophysiol 94:1789-1797. CrossRef Medline

Weyand TG (2007) Retinogeniculate transmission in wakefulness. J Neurophysiol 98:769-785. CrossRef Medline

Wimmer RD, Schmitt LI, Davidson TJ, Nakajima M, Deisseroth K, Halassa MM (2015) Thalamic control of sensory selection in divided attention. Nature 526:705-709. CrossRef Medline 